\title{
SYNAPTIC RESPONSES AND ELECTRICAL PROPERTIES OF CELLS IN BRAIN SLICES OF THE MOUSE ANTEROVENTRAL COCHLEAR NUCLEUS ${ }^{1}$
}

\author{
DONATA OERTEL
}

\author{
Department of Neurophysiology, University of Wisconsin, Madison, Wisconsin 53706
}

Received December 13, 1982; Revised March 22, 1983; Accepted May 5, 1983

\begin{abstract}
Intracellular recordings were made from cells in brain slices of the anteroventral cochlear nucleus. Responses to electrical stimulation of the stump of the auditory nerve were: (1) all-or-none, following the stimulus with no delay, and insensitive to the removal of extracellular $\mathrm{Ca}^{2+}$, probably representing the firing of directly stimulated auditory nerve fibers, or (2) graded, excitatory postsynaptic potentials, with synaptic delays of about $0.7 \mathrm{msec}$, which were often followed by graded, inhibitory synaptic potentials with synaptic delays of $1.2 \mathrm{msec}$ or longer. The excitatory and inhibitory synaptic potentials were abolished by the removal of extracellular $\mathrm{Ca}^{2+}$. The result that delays of inhibitory synaptic responses were at least 2 times as long as those of excitatory ones indicates that probably an additional synapse was interposed. Responses to intracellularly injected current pulses show that cells in the anteroventral cochlear nucleus have one of two types of electrical characteristics. Type I properties are characterized by linear current-voltage relationships in the subthreshold voltage range and large, regularly firing action potentials in the suprathreshold range. Type II properties are characterized by nonlinear current-voltage relationships; suprathreshold depolarization elicits only one or two small action potentials. Type II characteristics are particularly well suited for maintaining the information contained in the timing and patterns of firing of the auditory nerve fibers.
\end{abstract}

Auditory nerve fibers carry sensory information from the cochlea, the site of the transduction of sound to electrical signals, to the cochlear nuclei of the brainstem. In mammals, auditory nerve fibers enter the cochlear nuclei, bifurcate, and contact cells of several morphological types in three anatomically distinct regions, each of which has a separate tonotopic representation of sound (Rose et al., 1959). The ascending branches of auditory nerve fibers innervate the anteroventral cochlear nucleus (AVCN), the descending branches innervate the posteroventral and dorsal cochlear nuclei (Lorente de Nó,

\footnotetext{
${ }^{1}$ Chris Kintner collaborated with me in the early stages of developing the slice preparation. I especially thank the staff of the Department of Neurophysiology for their help in technical matters. I also thank J. Dodd for her valuable advice; W. Rhode, B. Sugden, S. -H. Wu, D. K. Morest, and B. W. Warr also made valuable suggestions. J. Brugge, C. Kintner, B. Sugden, J. Hirsch, and K. Marsh read the manuscript critically, for which I am very grateful. W. Welker supplied the photograph of the whole brain in Figure 1. This work was supported by National Institutes of Health Grants NS 17591 (to D. O.) and NS 12732 (to J. Hind). Funds from the University of Wisconsin, Madison, Graduate School Research Committee and from the Medical School Research Committee helped me to set up the laboratory.
}

1933a, 1981). Circuitry intrinsic to the cochlear nuclei and efferent input from other parts of the brain contribute to the transformation of signals (Lenn and Reese, 1966; Rasmussen, 1967; Cant and Morest, 1978; Lorente de Nó, 1981). The experiments discussed in this paper describe the electrical properties and the characteristics of the auditory nerve synaptic inputs of cells in the AVCN, showing how signals are transformed at this early stage in the auditory pathway.

In Golgi-stained material there are two distinct cell types in the AVCN, bushy cells and stellate cells (Brawer et al., 1974; Lorente de Nó, 1981; Webster and Trune, 1982). Stellate cells vary in size and shape; in the cat they have been subdivided by anatomists in different ways (Cant, 1981; Lorente de Nó, 1981). The organization of the AVCN and the morphology of its cells in the mouse resemble those of the cat (Lorente de Nó, 1933b; Osen, 1969; Brawer et al., 1974; Martin, 1981; Webster and Trune, 1982). Bushy cells receive input from the auditory nerve mainly through very large terminals called the end bulbs of Held (Lenn and Reese, 1966; Brawer and Morest, 1975; Cant and Morest, 1979; Ryugo and Fekete, 1982). Stellate cells receive input from the audi- 
tory nerve through more conventional button synapses (Cant, 1981).

Various attempts have been made to correlate anatomical cell types with physiological response types. The waveforms of extracellularly recorded action potentials in the AVCN vary in that some have prepotentials and others do not. Pfeiffer (1966b) suggested that prepotentials might reflect the depolarization of end bulbs of Held, implying that recordings with prepotentials are from bushy cells and those lacking prepotentials are presumably from stellate cells. Cells in the AVCN have also been characterized on the basis of their response patterns to pure tones at the characteristic frequency. Two distinct patterns of peristimulus time histograms, the "primary-like" and the "chopper" patterns, have been recorded. Cells with prepotentials have primary-like patterns. By means of intracellular injection of horseradish peroxidase into physiologically characterized cells, Rhode et al. (1983) have associated primary-like responses with bushy cells.

Very few intracellular recordings from the AVCN have been published (Starr and Britt, 1970; Romand, 1978; Rhode et al., 1983). These studies show that choppers are apparently driven by steady depolarizations which last for the duration of the tone pulse. Cells with primarylike patterns respond to tones with rapid, large, graded depolarizations which maintain the temporal pattern of the input with precision. In the nucleus magnocellularis, the avian homologue of the mammalian AVCN, large, rapid excitatory postsynaptic potentials have also been recorded in vitro after electrical stimulation of the auditory nerve (Hackett et al., 1982).

Studies of the intracellular physiology of the cochlear nuclei in vivo are hampered by the technical difficulties of recording in the presence of blood pulsations and respiratory movements. The brain slice preparation described in this paper overcomes some of these difficulties and takes advantage of the fact that the extracellular environment can be manipulated in vitro. In addition, the interpretation of the synaptic responses in brain slices is simplified by the fact that cells do not fire spontaneously in vitro. Synaptic responses of cells in the AVCN to electrical stimulation of the auditory nerve consist of an early excitatory and, in some cells, a later inhibitory postsynaptic potential. Responses to intracellularly injected current pulses show that the electrical properties of cells in the AVCN are of two types, called type I and type II.

\section{Materials and Methods}

General procedure. Young mice, 14 to 28 days old, were obtained from a colony of inbred mice of the strain NFS (originally obtained from Dr. Rex Risser, University of Wisconsin, Madison, WI). The slices were prepared according to the method of Dingledine et al. (1980). An animal was decapitated and the head was immersed in warm $\left(31^{\circ} \mathrm{C}\right)$, oxygenated saline. The saline composition was $124 \mathrm{mM} \mathrm{NaCl}, 5 \mathrm{mM} \mathrm{KCl}, 1.2 \mathrm{mM} \mathrm{KH}_{2} \mathrm{PO}_{4}, 2.4 \mathrm{~mm}$ $\mathrm{CaCl}_{2}, 1.3 \mathrm{~mm} \mathrm{MgSO}$, $26 \mathrm{~mm} \mathrm{NaHCO}, 10 \mathrm{~mm}$ glucose. When saturated with $95 \% \mathrm{O}_{2}, 5 \% \mathrm{CO}_{2}$, the $\mathrm{pH}$ was 7.4 . The brain was quickly dissected out of the skull, cutting the auditory nerve in the internal auditory meatus to leave the stump as long as possible. The tissue block containing the cochlear nuclei was then attached to a Teflon block with cyanoacrylate glue (Krazyglue). Slices were cut with an oscillating tissue slicer (Frederick Haer \& Co.). The most lateral, approximately parasagittal slice of the brainstem, $250 \mu \mathrm{m}$ thick, contained the auditory nerve and the lateral parts of the AVCN and the posteroventral cochlear nucleus as illustrated in Figure 1. This slice was transferred to the recording chamber where it was placed over a groove in the chamber floor. The chamber design allowed saline to flow from one end of the chamber to the other, passing under, as well as over,

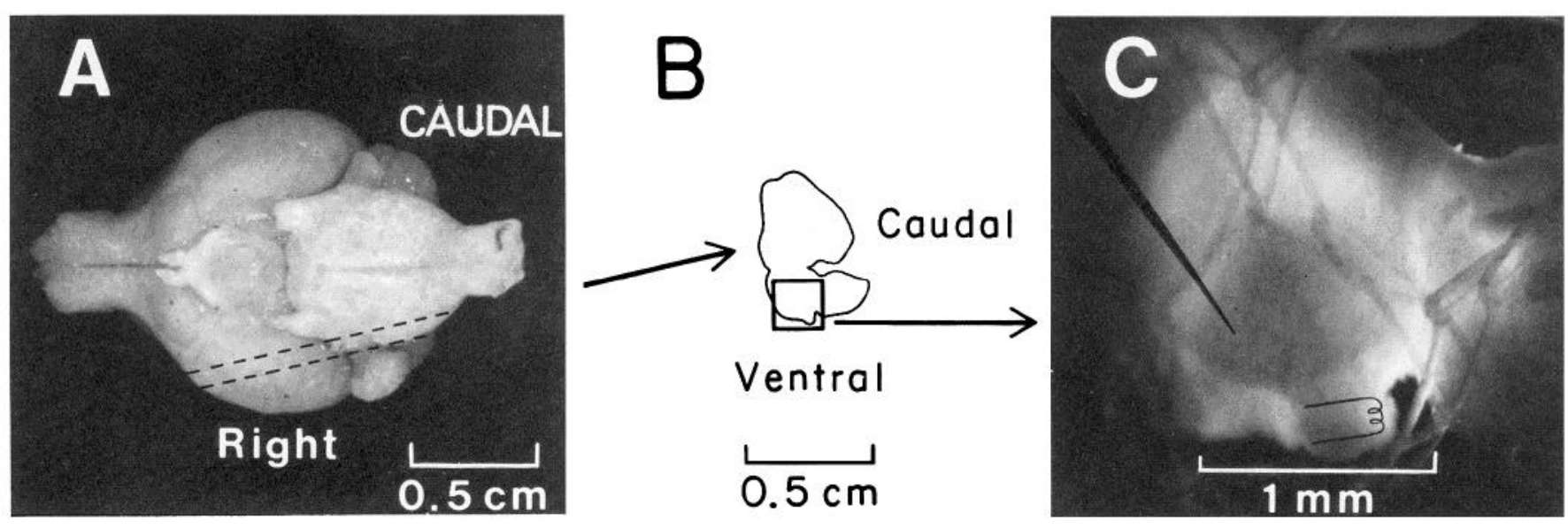

Figure 1. Preparation of slices of the cochlear nuclei. A, View of the ventral surface of the brain of a mouse with lines indicating approximately where cuts were made. $B$, Drawing of a slice. The stump of the auditory nerve and the cochlear nuclear complex is shown at the rostroventral edge. A portion of the cerebellum is attached dorsally and a portion of the medulla is attached caudally. An enlargement of the cochlear nuclear complex, shown in the square, is shown in $C$. $C$, A photograph of a preparation of the cochlear nuclear complex in the recording chamber. Darkfield illumination makes fascicles of auditory nerve fibers visible; the triangular region of bifurcation lies just over the point of entry of the auditory nerve into the brainstem. Nylon gauze was used to hold the preparation in place. Recordings were made rostral to the region of bifurcation; the stump of the auditory nerve was stimulated through a suction electrode or through a pair of insulated tungsten electrodes. 
the tissue. The slice was held in place with nylon gauze (Fig. 1C). The perfusion rate through the $0.3-\mathrm{ml}$ chamber was about $5 \mathrm{ml} / \mathrm{min}$. The temperature was kept at $35^{\circ} \mathrm{C}$ by a small thermistor (Yellow Springs Instrument $\mathrm{Co}$.) and a feedback-controlled electric heater. The auditory nerve was stimulated through a suction electrode or through a pair of insulated tungsten electrodes.

Electrophysiology. Intracellular recordings were made by conventional means. Intracellular voltage was measured using a DAGAN Single Electrode System, displayed on an oscilloscope screen, from which it could be photographed, and recorded on a chart recorder. The microelectrodes, filled with $4 \mathrm{M}$ potassium acetate, had resistances of 120 to 200 megohms and were coated with dichlorodimethyl silane.

The preparation. The transparent chamber was illuminated from below through a darkfield condenser (Leitz D 0.80). With such illumination, myelinated fiber bundles can be distinguished from cell bodies. The region of bifurcation of the auditory nerve fibers is visible as a triangle just dorsal to the entry of the auditory nerve into the brainstem (Fig. $1 C$ ). All recordings reported in this paper were made anterior to the region of bifurcation.

Since electrophysiological responses of unhealthy tissues are not useful and since mammalian brain tissue is difficult to maintain in vitro, it is essential to learn to distinguish active slices from unhealthy ones. With experience this becomes very clear because the symptoms of unhealthy slices are consistent. They are similar to the symptoms of bad preparations of cat cochlear nuclei in vivo (W. S. Rhode, D. Oertel, and P. H. Smith, unpublished observations). In some slices synaptic responses to electrical stimulation of the auditory nerve were encountered with almost every microelectrode penetration. Intracellular current injection revealed long time constants and brief, large action potentials. Once the slices recovered from the trauma of cutting, after 1 to $2 \mathrm{hr}$, such active slices remained stable for more than $10 \mathrm{hr}$. Responses of single cells also remained stable. For example, the intracellular recordings from the cells depicted in Figures 4 through 9 each lasted for over $3 \mathrm{hrs}$. The responses at the end of that period were not measurably different from those at the beginning. In other slices only a few responses could be recorded during the first few hours of the experiment and eventually none could be recorded. Under conditions that promote anoxia, such as if slices are too thick, if they are prepared too slowly, if the perfusion rate is too slow, if the temperature is too high, or if the tissue is perfused on only one side, the cells become visibly swollen. Swollen cells initially have very large resting potentials, -70 to -80 $\mathrm{mV}$, and very short time constants, and they are electrically and synaptically inexcitable. Occasionally the transition between being electrically excitable and becoming inexcitable has been observed while the electrode was in a cell. This indicates that the swollen cells are sometimes, if not always, neurons. With time, microelectrode penetrations into swollen areas encountered no electrically active cells and no cells with large resting potentials. The pathological changes described above are irreversible.

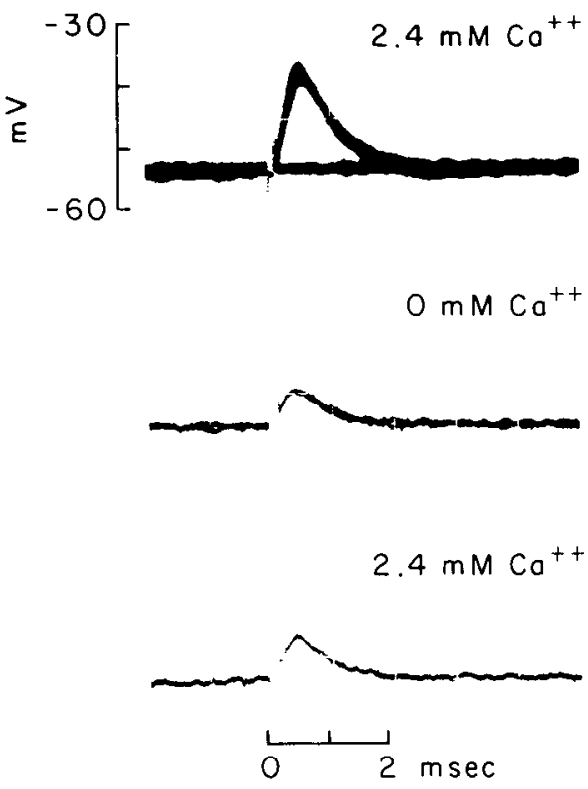

Figure 2. Response of what is probably an auditory nerve fiber to electrical stimulation of the auditory nerve. Upper traces, Ten superimposed responses to stimulation of the auditory nerve, while the voltage was varied around the threshold, show that the response is all-or-none. Stimulating pulses of about $5 \mathrm{~V}, 0.1 \mathrm{msec}$, were applied to the stump of the auditory nerve through a suction electrode. Stimulus artifacts are seen as a gap in the traces. Responses followed the stimuli with no detectable delay. Middle traces, The response of the same cell remained when $\mathrm{Mg}^{2+}$ was substituted for $\mathrm{Ca}^{2+}$ in the saline. Lower trace, When the saline was again returned to normal, there was no change in the response. The observation that the response gradually became smaller was a consistent feature of recordings from this type of cell, which tended to be unstable. The mouse was 22 days old.

After many experiments the structures of the tissue was examined microscopically. Slices were fixed and embedded in $2 \%$ agar. Frozen sections were cut, mounted, and stained with cresyl violet. The difference in cellular structure between active and unhealthy slices supported the observations made while recording. The nuclei of unhealthy cells were swollen. In some preparations the nuclei of neurons seemed to disintegrate. In contrast, the appearance of active tissue, even after a long experiment, is like that of normal brain tissue fixed by perfusion through the heart.

\section{Results}

The results presented here represent recordings from more than 150 cells in 38 preparations. Many of the recordings, however, were from cells that were not well impaled, were too brief to be useful, or were from slices which were not healthy (see "Materials and Methods").

One sort of response to stimulation of the auditory nerve stump ( 1 to $10 \mathrm{~V}, 0.1 \mathrm{msec}$ ) that was encountered regularly in the AVCN and in the auditory nerve is shown in Figure 2. Uppermost is a record of 10 traces that were superimposed while the voltage of the stimulating pulse was varied around the threshold of the response. This record shows that an all-or-none action potential follows the stimulus artifact with no observable delay. Although 
the amplitude of the recorded action potential diminished with time, a consistent feature of this sort of response, the action potential remained when extracellular $\mathrm{Ca}^{2+}$ in the saline was replaced with $\mathrm{Mg}^{2+}$, (Fig. 2, middle trace). Such cells were never observed to fire spontaneously or in response to damage by the microelectrode; they could follow rates of stimulation up to about $1000 / \mathrm{sec}$. The findings that these responses are all-or-none, independent of extracellular $\mathrm{Ca}^{2+}$, and follow the stimulating pulse with no delay indicate that they are not mediated by chemical synaptic transmission. These results and the observation that such responses can be recorded frequently in the auditory nerve are consistent with the conclusion that such recordings are from auditory nerve fibers.

Intracellular recordings were also made from cells whose responses to electrical stimulation of the auditory nerve were mediated by chemical synaptic transmission; these recordings presumably were from cells in the AVCN which receive synaptic input from the auditory nerve. These cells responded to electrical stimulation of the auditory nerve with a $\mathrm{Ca}^{2+}$-dependent excitatory postsynaptic potential (EPSP) after a delay of about 0.7 msec. In many cells the early EPSP was followed by a later inhibitory postsynaptic potential (IPSP); the presence of the IPSP was uncertain in some cells because it could not be distinguished from the undershoot of the action potential of a suprathreshold, excitatory response. The thresholds of the EPSPs and IPSPs were different in some cells (e.g., Fig. 6), indicating that excitation and inhibition are not mediated by exactly the same population of auditory nerve fibers. Excitatory and inhibitory synaptic responses were graded with the strength of the stimulating pulses; the duration of stimulating pulses was kept constant at $0.1 \mathrm{msec}$.

The responses of cells in the AVCN to intracellularly injected current pulses revealed membrane properties of two types. Cells with type I characteristics responded to depolarization with large, regularly firing action potentials. The current-voltage relationship of type I responses in the voltage range more negative than the firing threshold was linear. In contrast, depolarization elicited only one or two brief but small action potentials in cells with type II properties. The responses to hyperpolarizing current pulses rectified with time. The current-voltage relationship of cells with type II characteristics was not linear.

Type I characteristics. Cells with type I responses react to stimulation of the auditory nerve with an EPSP that appears to be truncated by a temporally overlapping IPSP. The amplitudes of both the EPSP and IPSP are graded as a function of stimulus strength. Intracellular recordings from such a cell are shown in Figure 3. The top panel illustrates responses to electrical stimulation of the auditory nerve at various strengths. Stimulation at low voltage produced a graded depolarization lasting about 2 msec. Stimulation of the auditory nerve at slightly higher voltage, which presumably activated additional auditory nerve fibers, caused the EPSP to become suprathreshold. The bottom panel shows that the synaptic response consisted of an early EPSP followed by a later IPSP which reversed at the resting potential.
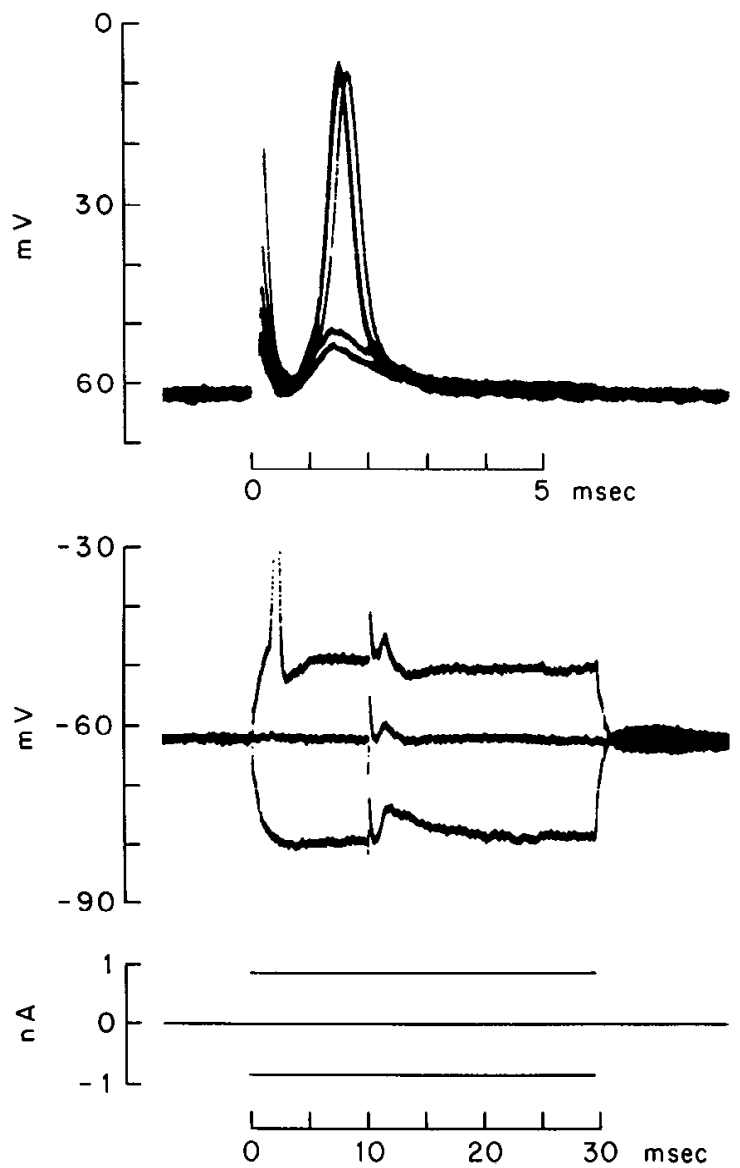

Figure 3. Characteristics of a type I cell. Upper panel, Five superimposed responses to electrical stimulation of the auditory nerve at various voltages, $0.1 \mathrm{msec}$ duration. Initial deflection of the voltage trace is the stimulus artifact. Excitatory synaptic responses are graded with stimulus strength. Lower panel, Characteristics of the synaptic response as a function of membrane voltage. Three responses are superimposed; injected current was varied. The synaptic response consists of two components, an EPSP which is depolarizing under all three conditions and a later IPSP which is depolarizing while the cell is hyperpolarized, hyperpolarizing while the cell is depolarized, and which reverses at resting potential. Responses to current pulses of opposite polarity and equal amplitude are approximately symmetrical around the resting potential. These records were made from the same cell as in Figure $10 \mathrm{~A}$. The mouse was 22 days old.

In this experiment the cell was polarized with current pulses while it responded to electrical stimulation of the auditory nerve. The voltage changes resulting from current pulses of equal magnitude and opposite polarity were approximately symmetrical. Depolarizing current pulses of $1 \mathrm{nA}$ elicited regularly firing action potentials. The results of these experiments, therefore, indicate that the cell was both excited and inhibited by the stimulation of auditory nerve fibers. In other cells of type I the thresholds for excitation and inhibition were different, indicating that excitation and inhibition are not necessarily mediated by the same population of auditory nerve fibers.

The responses to stimulation of the auditory nerve of a second cell with type I characteristics are shown in 
Figure 4. Like the cell described above, this neuron responded to stimulation of the auditory nerve with a graded EPSP that appeared truncated. The two lower panels of Figure 4 show responses to stimulation of the auditory nerve with shocks of low strength (left) and high strength (right) while the cell was simultaneously polarized with current. Again, the later inhibitory component of the synaptic response became apparent only when the cell was polarized because it reversed at the resting potential. In the cell whose responses are illustrated in Figure 4, the threshold for inhibition was slightly lower than that for excitation so that the duration of the EPSP could not be determined. In each of the lower panels the traces show responses to current injection of equal magnitude but opposite polarity. The voltage responses to injection of current of type I cells appear symmetrical and indicate that the input resistance of the cell remained constant. 'I'his is shown more clearly in Figure 5. The current-voltage relationship, determined for this cell from traces such as those on the right, is approximately linear below its firing threshold. A depolarizing current of about $0.4 \mathrm{nA}$ brought the membrane voltage past threshold causing the cell to fire large action potentials. Large, steady depolarizations caused very regular firing. The time constant of this cell was approximately $5 \mathrm{msec}$.

Type II characteristics. Cells with type II characteristics also respond to stimulation of the auditory nerve with an early EPSP followed by a later IPSP. It is their responses to intracellularly injected current pulses that distinguish them from type I cells. The responses of such a cell to electrical stimulation of the auditory nerve at three different voltages are shown in Figure 6. The response with the lowest threshold was an IPSP in this cell. At slightly greater stimulating voltage, a small EPSP preceded the IPSP. At even greater voltage, a large, apparently suprathreshold EPSP was followed by a hyperpolarization. Depolarizing current elicited a single, small action potential that was followed by only a small, hyperpolarizing undershoot (Fig. 7A). The synaptic response while the cell was polarized with current was larger than the action potential alone and it was followed by a larger hyperpolarization. It is impossible to distinguish the inhibitory synaptic response from the undershoot that accompanied the action potential of the suprathreshold response because they occurred simultaneously. The response to hyperpolarizing current of the same magnitude was large and had a longer time con-
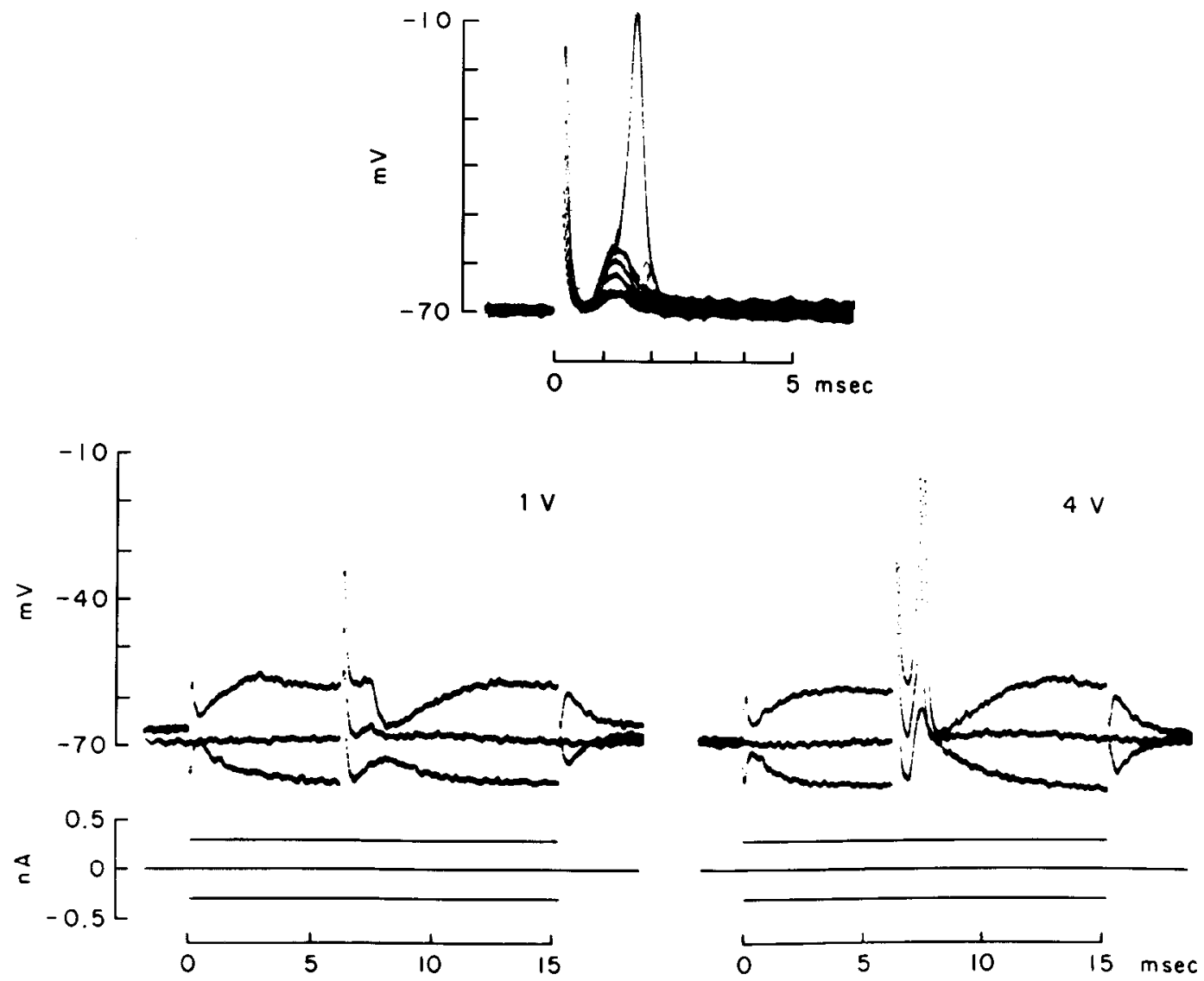

Figure 4. Characteristics of a type I cell. Top, Five superimposed responses to electrical stimulation of the auditory nerve with shocks of various strengths, $0.1 \mathrm{msec}$ duration. The excitatory synaptic response is graded and can initiate a large action potential. Bottom, When the cell is polarized with current, synaptic responses can be seen to consist of an early depolarizing EPSP which is followed by an IPSP that reverses at about resting potential. At the left, the synaptic responses are subthreshold; at the right they are suprathreshold. Each panel shows three superimposed responses to stimulation of the auditory nerve while the amount of current injected into the cell is varied. The responses to current pulses of equal size but opposite polarity are symmetrical around the resting potential. The mouse was 24 days old. 


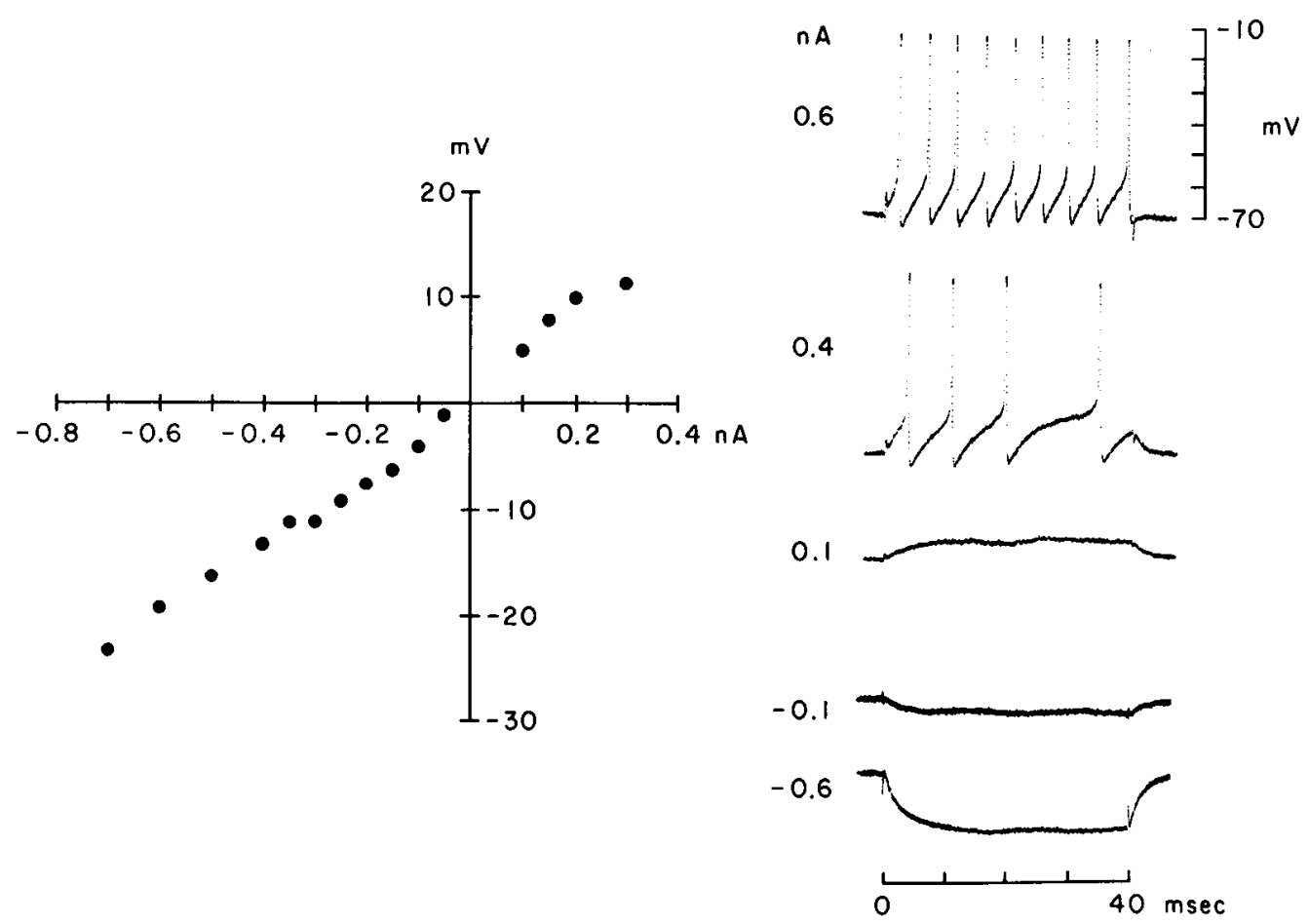

Figure 5. Current-voltage relationship of a type I cell. Traces on the right show responses to current pulses. The numbers on the left indicate the current strength in nanoamperes. Depolarizing current pulses greater than $0.3 \mathrm{nA}$ caused the cell to fire action potentials. On the left the voltage change, measured at the end of the $40-\mathrm{msec}$ pulse, is plotted as a function of current strength. The relationship is approximately linear. These responses were recorded from the same cell as those of Figure 4 . The mouse was 24 days old.
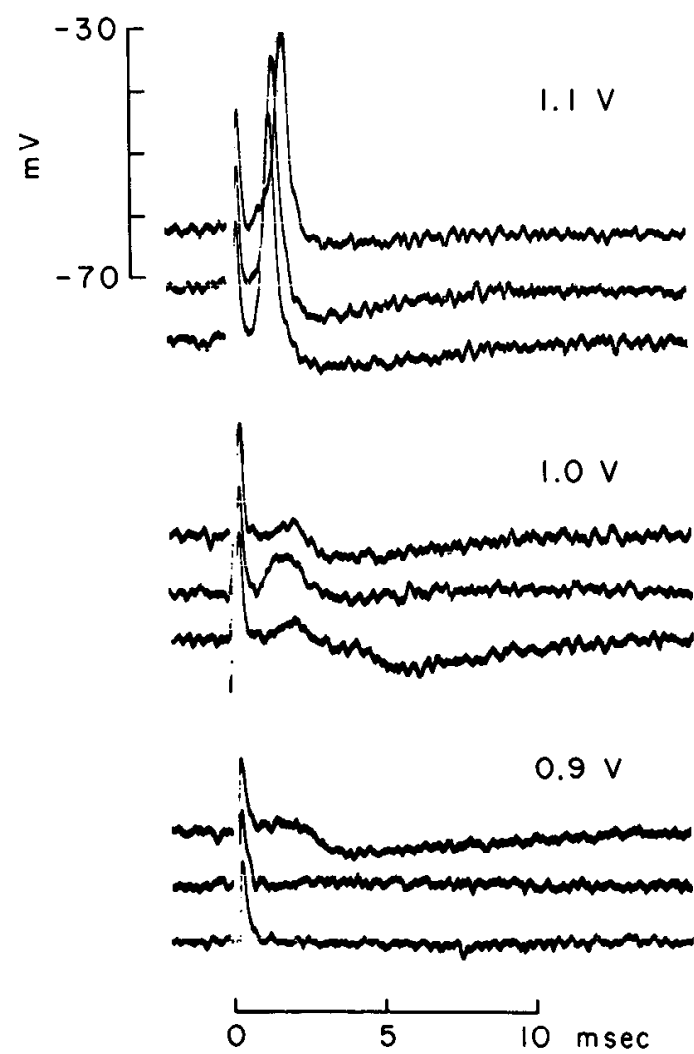

Figure 6. Synaptic responses of a type II cell. Responses to electrical stimulation of the auditory nerve at different voltages. The response with the lowest threshold $(0.9 \mathrm{~V})$ was an inhibitory one which occurred with a delay of about $2 \mathrm{msec}$ and lasted stant. The synaptic response was very large and was followed by a slow depolarization. It appears that the undershoot reversed at a level lower than the resting potential but its shape was altered by the cell's variable membrane properties. To study type II membrane properties further, the responses to long current pulses were measured and the current-voltage relationship was plotted (Fig. 8). The records show that depolarization elicited a single action potential and a small voltage change, whereas hyperpolarizing current pulses produced large voltage changes. Large hyperpolarizations sagged back toward the resting potential, showing anomalous rectification (Armstrong and Binstock, 1965). The currentvoltage relationship was nonlinear.

Both the small slope resistance and the short time constants of responses to depolarizations suggest that the input resistance of this cell was low when the cell was depolarized with current. The experiment illustrated in Figure 9 tests this prediction directly. On the left are responses to long depolarizing and hyperpolarizing current pulses of equal magnitude. To monitor the input resistance before, during, and after polarization, small hyperpolarizing current pulses were injected. The input

about $10 \mathrm{msec}$. Stimulation with pulses at higher voltage elicited early EPSPs of various amplitudes which were followed by IPSPs. Shocks of still higher voltage elicited large, brief depolarizations of variable amplitude which were followed by hyperpolarizing undershoots. These records were made from the same cell as that in Figures $7 A, 8$, and 9 . The mouse was 27 days old. 
resistance was indeed lower when the cell was depolarized with current (Fig. 9, top right). The input resistance was also slightly lowered by hyperpolarizing currents while the cell showed anomalous rectification. When the cell repolarized after the end of the hyperpolarization, the input resistance was temporarily low and gradually returned to its resting value.

The experiments described above were all performed on a single cell. The traces in Figure $7 B$ show the responses of a different cell in a different slice. The electrical properties of this cell resemble those of the first in that the voltage change and time constant of responses to depolarizing current were small and those of the responses to hyperpolarizing current were large. The depolarizing current pulse elicited two action potentials in this cell.

Summary of results. It is unlikely that the dichotomy between type I and type II cells is simply a result of a difference in resting potentials since the resting potentials of cells with type I properties were not significantly different from those with type II properties (Table I).

Table I also summarizes some of the features of the synaptic responses. The delay between the beginning of the stimulating pulse $(0.1 \mathrm{msec}$ duration) and the excitatory synaptic response can be measured accurately and is usually between 0.6 and $0.7 \mathrm{msec}$. The duration of an EPSP in the AVCN can be measured accurately only rarely because often it is cut short by an inhibitory synaptic potential or it is obscured by an action potential. In addition, the measurements can be made only at the lowest stimulating voltages, biasing the measurements toward short durations. The delays and durations of IPSPs can also be made most often only at the lowest stimulating voltages, biasing the measurements toward long delays and short durations. At large stimulating voltages, the EPSP usually becomes suprathreshold and an action potential and its undershoot obscure the underlying synaptic responses. The result that the shortest observed delay of the inhibitory response is about twice as long as the shortest excitatory response is consistent with the conclusion that the EPSP is mediated by a single synapse and that the IPSP is mediated through two synapses. No recordings have been made from cells that did not respond to stimulation of the auditory nerve with an excitatory synaptic response.

Temporal summation of excitation in type I and type II cells. The finding that the drop in input resistance of cells with type II characteristics with depolarization can be large has functional implications. This feature of type II cells reduces temporal and spatial summation and makes them well suited to maintaining and conveying precisely timed pattern information from the auditory nerve. In contrast, cells with type I characteristics have longer time constants, suggesting that temporal summation might occur.

The experiments illustrated in Figure 10 test this hypothesis directly. Figure $10 \mathrm{~A}$ shows responses of a type I cell to repetitive stimulation of the auditory nerve. The responses to one or two shocks $1.2 \mathrm{msec}$ apart were subthreshold. A third shock enabled the subthreshold EPSPs to sum and depolarize the cell past its threshold. This cell responded to stimulation of the auditory nerve with an inhibitory as well as an excitatory synaptic potential (Fig. 3). Temporal summation of excitatory inputs would be more pronounced in the absence of inhibition.

The results of a similar test of a cell with type II
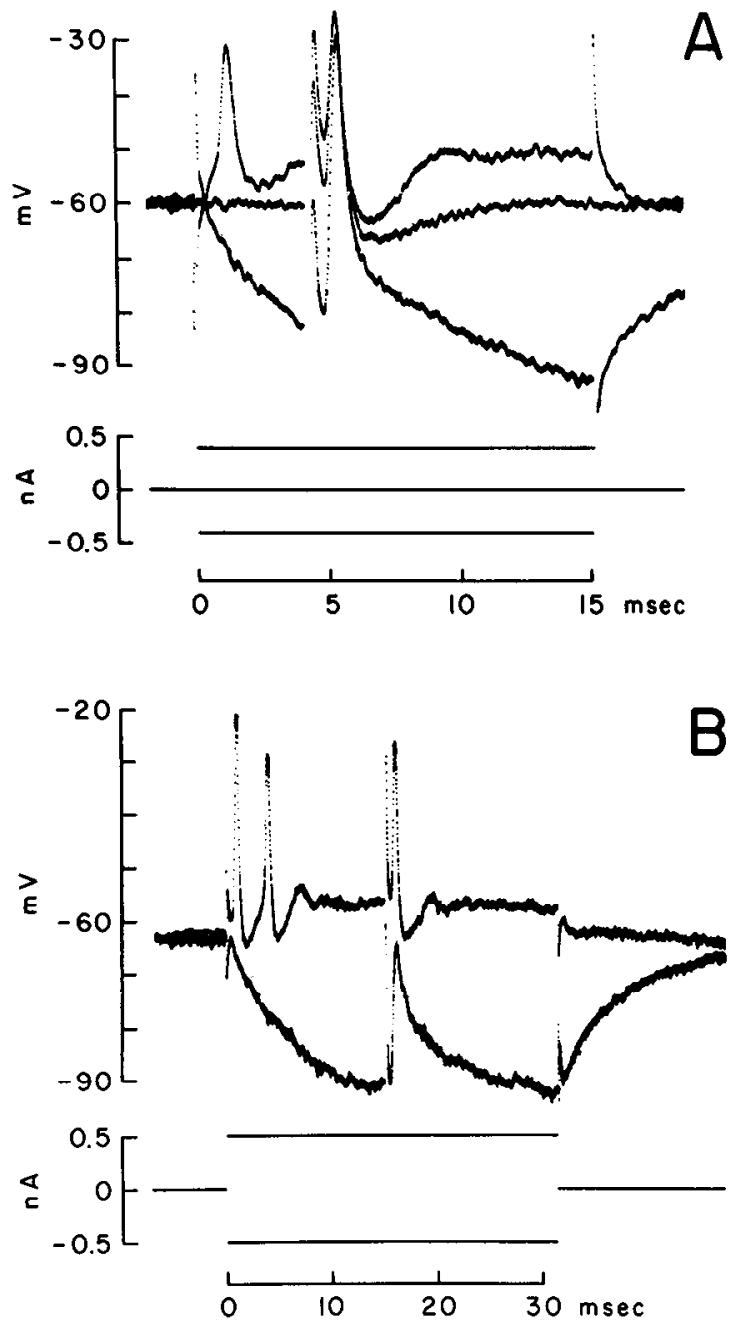

Figure 7. Synaptic responses of two different cells in two different preparations recorded while the cells were polarized with current. $A$, Three superimposed synaptic responses while the cell was not polarized, depolarized and hyperpolarized with current. Depolarization elicited a single action potential with a small undershoot. Electrical stimulation of the auditory nerve, while the cell was depolarized with current, depolarized the cell further than the action potential. This was followed by hyperpolarization which dipped below the resting potential. Hyperpolarizing current polarized the cell slowly. The peak of the synaptic response while the cell was hyperpolarized almost reached the peak of the response while the cell was depolarized. A slow depolarization followed the rapid EPSP which represents the reversed IPSP and/or the reversed undershoot of the action potential. Both the amplitude of the depolarizing and hyperpolarizing voltage changes and their time courses were different. The varying membrane properties distort the synaptic potentials differently when the cell is depolarized than when it is hyperpolarized. These records were made from the same cell as that of Figures 6,8 , and 9 . The mouse was 27 days old. $B$, The results of a similar experiment performed on a different type II cell in a different preparation show that the synaptic responses and the membrane properties of type II cells are consistent. This cell fired two action potentials when it was depolarized with current. This cell was the same as that of Figure $10 B$. The mouse was 22 days old. 

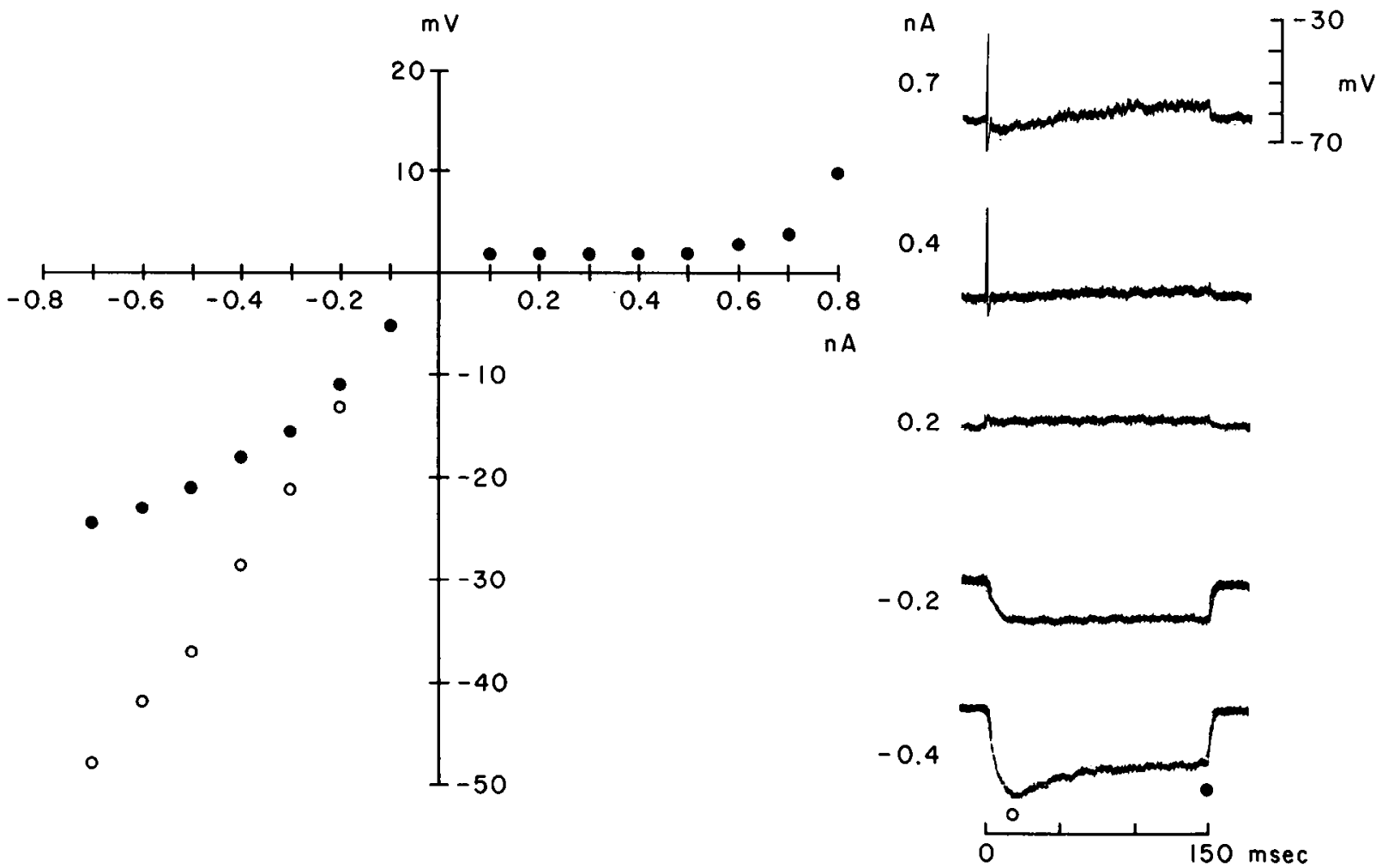

Figure 8. Type II cell responses to intracellularly injected current. Responses to long current pulses are shown on the right. Numbers on the left of the traces indicate current strength in nanoamperes. Depolarizing current elicits a single action potential and a small voltage change. Hyperpolarizing current produces a hyperpolarization which is initially large and which slowly sags back toward the resting potential. The voltage changes measured at the end of the long current pulses are plotted as a function of current strength on the left $(0)$. Peak voltage of hyperpolarizations are also plotted $(O)$. The current-voltage relationship is not linear. Measurements are made from the same cell as in Figures 6 and $7 A$, and 9 . The mouse was 27 days old.
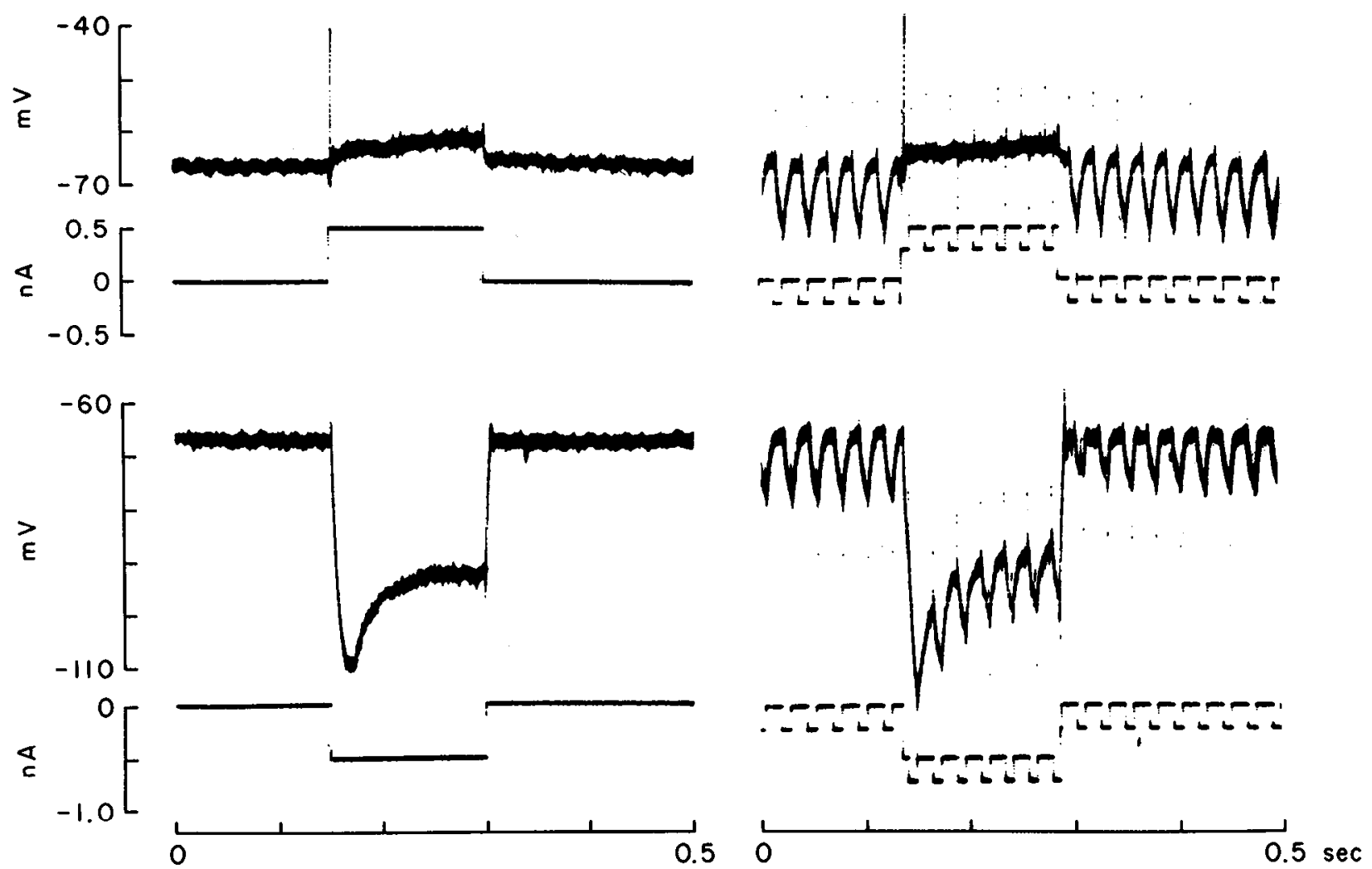

Figure 9. Input resistance of a type II cell while it is polarized with current. Left, Responses to depolarizing and hyperpolarizing current pulses. Right, Small hyperpolarizing current pulses were superimposed on the long pulses to monitor the input resistance of the cell. While the cell was depolarized the input resistance was reduced. Only a small change in input resistance accompanied anomalous rectification while the cell was hyperpolarized. After the end of the hyperpolarization the input resistance slowly increased to its resting value. These records were made from the same cell as those in Figures $6,7 A$, and 8 . The mouse was 27 days old. 
TABLE I

Characteristics and synaptic responses of AVCN cells

The means and ranges of measured values are shown for several characteristics of cells in the AVCN. Whenever possible, the resting potentials were measured at the end of a recording when the electrode was withdrawn from a cell. In cases when the recording degenerated the measurement was made earlier in the record. The height of action potentials was measured from the peak to the bottom of the undershoot. Synaptic delays were measured from the beginning of stimulating pulses, $0.1 \mathrm{msec}$ in duration, to the beginning of the change in cell voltage. Measurements of EPSPs could be made accurately; measurements of the duration of EPSPs was not possible if an action potential was superimposed or if an IPSP followed; therefore, most measurements are made from less than maximal synaptic responses. Similarly, IPSP delays and durations could only be measured in the absence of action potentials. Since the delay of a synaptic response that is barely suprathreshold can be longer than that of a maximal response, the measurements of IPSP delays are biased toward long delays. Since the duration of small synaptic responses sometimes appears shorter than that of large synaptic responses, the measurements of the duration of IPSPs are biased toward short durations.

\begin{tabular}{ccc}
\hline Mean & Range & $\begin{array}{c}\text { No. of } \\
\text { Cells }\end{array}$ \\
\hline \multicolumn{2}{c}{$m V$}
\end{tabular}

Resting potentials

Type I
Type II
?

Action potentials

Type I

Iype II

?

Total

\section{EPSP delays}

Type I

Type II

?

Total

EPSP durations

Type I

Type II

?

Total

IPSP delays

Type I

Type II

?

Total

IPSP durations

Type I

Type II

?

Total

$\begin{array}{rr}-61 & -54--69 \\ -60 & -53--65 \\ -55 & -53--58 \\ -60 & -53--69 \\ & \\ 58 & 30-80 \\ 28 & 15-55 \\ 48 & 15-70 \\ 45 & 15-80\end{array}$

9
8
3
20

20

9

8

3

20

$\begin{array}{rr}0.5-1.4 & 9 \\ 0.6-0.8 & 8 \\ 0.6-0.7 & 3 \\ 0.5-1.4 & 20 \\ & \\ 3.5-6.0 & 3 \\ 1.5-2.6 & 3 \\ & 1 \\ 1.5-6.0 & 7 \\ & \\ 1.2-3.5 & 6 \\ 2.0-2.3 & 3 \\ 2.0-2.5 & 3 \\ 1.2-3.5 & 12 \\ & \\ 5.0-10 & 6 \\ 4.0-9.0 & 3 \\ 5.0-6.0 & 2 \\ 4.0-10 & 11\end{array}$

characteristics is shown in Figure $10 B$. The synaptic responses of two shocks about $1.2 \mathrm{msec}$ apart are brief and clearly separated. It was not clear whether this cell's synaptic response contained an inhibitory component (Fig. $7 B$ ).

\section{Discussion}

Intracellular recordings from cells in the AVCN in vitro show that electrical stimulation of the auditory nerve produces not only excitatory but also inhibitory synaptic responses. Both the EPSP and the IPSP are graded in amplitude as a function of stimulating voltage. Excitation always occurs with a shorter latency than does inhibition; the delay from the shock to the excitatory response was 0.6 or $0.7 \mathrm{msec}$, that to the inhibitory response was $1.2 \mathrm{msec}$ or longer. Cells in the AVCN had one of two kinds of membrane properties under the conditions of these experiments. Cells with type I characteristics have linear current-voltage relationships and they fire action potentials regularly in response to steady depolarization. Cells with type II characteristics have nonlinear current-voltage relationships and they respond to intracellularly injected, depolarizing current with only one or two action potentials. The input resistance of type II cells is reduced during depolarization. The responses to hyperpolarizing current show anomalous rectification (Armstrong and Binstock, 1965). Temporal summation of excitatory synaptic inputs is more likely to occur in cells with type I than in cells with type II characteristics.

Several conclusions can be made from these results. The finding that the excitatory inputs of type I cells are
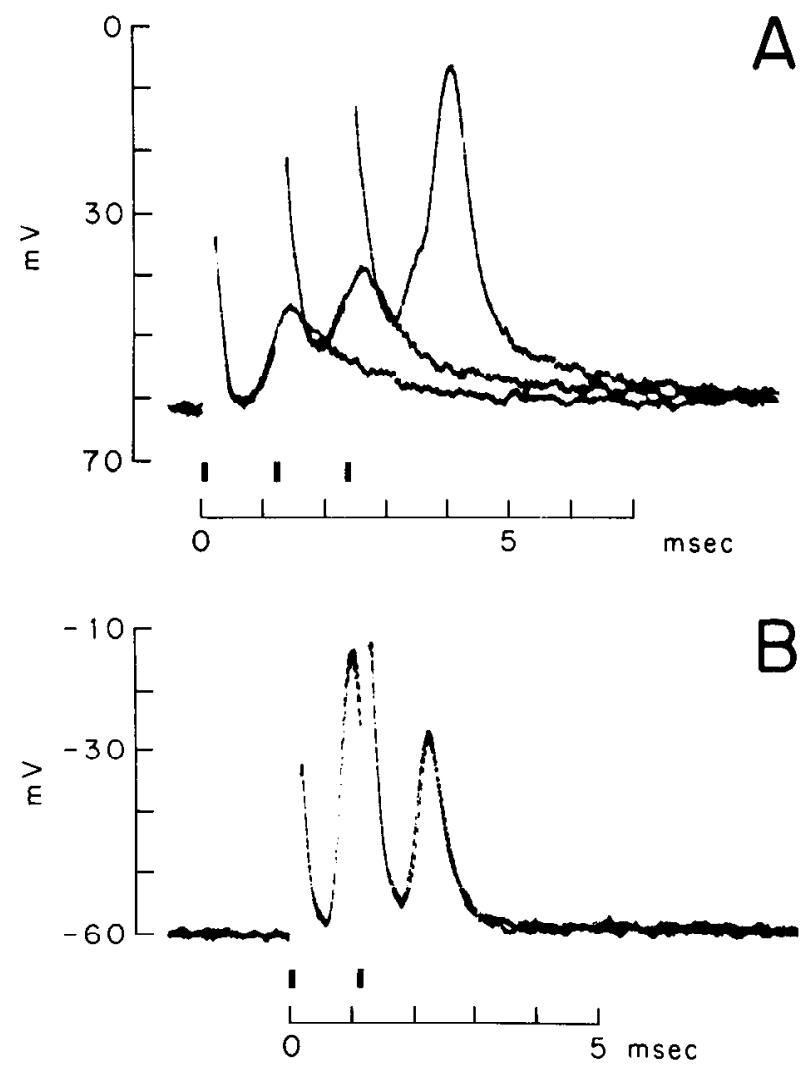

Figure 10. Temporal summation of excitatory synaptic inputs. A, Responses of a type I cell to repetitive stimulation of the auditory nerve. Responses are superimposed to one, two, and three stimulating pulses. Subthreshold EPSPs can sum in time to produce a suprathreshold response. This was the same cell from which the records were made shown in Figure 3 . The mouse was 22 days old. $B$, Response of a type II cell to repetitive stimulation of the auditory nerve. Responses to two stimuli did not sum in time. Two traces were superimposed. This was the same cell from which the record shown in Figure $7 B$ was made. The mouse was 22 days old. Bars indicate when the auditory nerve was stimulated. 
graded with the strength of electrical stimulation of the auditory nerve shows that simultaneous inputs from several auditory nerve fibers can be summed. In addition, it has been demonstrated directly that repetitive inputs from any one auditory nerve fiber can sum in time (Fig. $10 \mathrm{~A}$ ). Excitatory inputs of type II cells are also graded showing that simultaneous inputs from more than one auditory nerve fiber can sum, but it is unlikely that excitatory inputs of any one fiber sum in time. The drop in input resistance of type II cells when they are depolarized reduces both the time and space constants and thus reduces summing in time and space. Excitatory synaptic potentials in type II cells are large, but they are only about $1 \mathrm{msec}$ in duration. It has been shown that temporal summation in cells with type II characteristics does not occur at physiological stimulation rates (Fig. $10 B$ ). Type II cells are, therefore, particularly well suited to preserve the pattern and timing information contained in the firing of auditory nerve fibers. The synaptic currents underlying EPSPs in type II cells must be large; the experiment illustrated in Figure 7 shows that type II cells can be synaptically excited even when the input resistance is low while they are depolarized with current.

Definitive morphological identifications with intracellular dye injections of cells with type I and type II characteristics have not yet been made, but several lines of evidence make it likely that type I cells correspond to stellate cells identified in Golgi-stained material and that type II cells correspond to bushy cells of Golgi-stained material (Webster and Trune, 1982). In the cat, cells with "chopping" peristimulus time histograms (Pfeiffer, 1966a) respond to tones with regularly firing action potentials whose pattern is not related to the sound stimulus. The regular rhythm could arise from intrinsic membrane properties such as those of type I cells. The responses to tones do consist of steady depolarizations which would be expected to cause type I cells to fire regularly (Molnar and Pfeiffer, 1968; Starr and Britt, 1970; Romand, 1978). Rhode et al. (1983) showed that choppers were stellate cells in the ventral cochlear nucleus. Type II cells do not have intrinsic regular firing rhythms; their properties correspond closely with those of the bushy cells (Rhode et al., 1983). Bushy cells respond to tones with large, brief, graded synaptic potentials which are capable of maintaining the pattern information to a precision greater than $1 \mathrm{msec}$. The strong, brief, graded synaptic responses of type II cells to stimulation of the auditory nerve have the characteristics required to generate the responses recorded in bushy cells (Rhode et al., 1983). Until intracellular dye injections into physiologically identified cells are made, however, the possibility that these contrasting electrical characteristics result from the in vitro conditions cannot be completely excluded.

The synaptic interactions between auditory nerve fibers and bushy cells are mediated through the large terminals called the end bulbs of Held (Lorente de Nó, 1933a, 1981; Lenn and Reese, 1966; Brawer and Morest, 1975; Cant and Morest, 1979). If type II characteristics are associated with bushy cells, the experiments described in this paper provide a clue concerning what the function of these endings might be. That the input re- sistance of type II cells drops sharply when the cells are depolarized means that they can repolarize quickly, the time constant of the cell being proportional to the input resistance. The fact that the synaptic current can depolarize type II cells even when the input resistance is low indicates that the synaptic current must be large and that the lowered input resistance does not result in a refractory period. The large end bulb terminals with their multiple release sites for neurotransmitter (Lenn and Reese, 1966; Cant and Morest, 1979) could provide unusually large amounts of synaptic transmitter which might result in the large synaptic current.

Both type I and type II cells receive late inhibitory as well as early excitatory inputs as a result of electrical stimulation of the auditory nerve. The result that the inhibitory response occurs with a delay at least twice as long as that of the excitatory one is consistent with the conclusion that an additional synapse is interposed. That inhibitory and excitatory responses have different thresholds to stimulation of the auditory nerve implies that the inputs are mediated through different auditory nerve fibers. Very little physiological evidence exists for inhibition in the AVCN. The only direct evidence is presented in a recent report by Martin and Dickson (1982) showing that excitation, induced by iontophoretic application of excitatory amino acids, can be suppressed by tones higher than the cell's characteristic frequency in cells lacking prepotentials. Evans and Nelson (1973) have shown that some cells in the $\Lambda V C N$ respond to tones with a suppression of spontaneous firing.

In the cat it has been shown that there are two types of spiral ganglion cells (Spoendlin, 1969; Liberman, 1982; Kiang et al., 1982). Type II auditory nerve fibers would be expected to conduct more slowly than the thicker type I fibers. It is possible, therefore, that the observed inhibitory input to cells in the AVCN might arise from type II fibers. The result that only terminals with large spherical vesicles are of cochlear origin (Lenn and Reese, 1966; Cant and Morest, 1979) argues against this possibility. Also, in the present series of experiments recordings were made from cells likely to be auditory nerve fibers. If one population of auditory nerve fibers conducted more slowly, then some responses would be expected to occur after a conduction delay; such responses have not been observed. It seems likely, therefore, that the inhibitory synaptic response arises indirectly from other cells in the cochlear nuclear complex. That is, electrical stimulation of the auditory nerve excites the cell from which a recording is made and also excites other cells in the slice preparation which in turn make inhibitory synaptic contacts onto the cell that is impaled.

The result that cells in the AVCN receive inhibitory as well as excitatory input is consistent with the anatomical observations that bushy cells and stellate cells are contacted by several types of terminals. In addition to the endings containing large spherical vesicles which have been shown to be of cochlear origin (Lenn and Reese, 1966; Cant and Morest, 1979), bushy cells and stellate cells are contacted by terminals containing small flattened or small pleomorphic vesicles which are not of cochlear origin (Cant and Morest, 1979; Cant, 1981). Some of the latter have been shown to be intrinsic to the 
cochlear nuclei and could thus mediate the inhibition observed in the brain slice.

\section{References}

Armstrong, C. M., and L. Binstock (1965) Anomalous rectification in squid giant axon injected with tetraethylammonium chloride. J. Gen. Physiol., 48: 859-872.

Brawer, J. R., and D. K. Morest (1975) Relations between auditory nerve endings and cell types in the cat's anteroventral cochlear nucleus seen with the Golgi method and Nomarski optics. J. Comp. Neurol. 160: 491-506.

Brawer, J. R., D. K. Morest, and E. C. Kane (1974) The neuronal architecture of the cochlear nucleus of the cat. J. Comp. Neurol. 155: 251-300.

Cant, N. B. (1981) The fine structure of two types of stellate cells in the anterior division of the anteroventral cochlear nucleus of the cat. Neuroscience 6: 2643-2655.

Cant, N. B., and D. K. Morest (1978) Axons from non-cochlear sources in the anteroventral cochlear nucleus of the cat. A study with the rapid Golgi method. Neuroscience 3: 10031029.

Cant, N. B., and D. K. Morest (1979) The bushy cells in the anteroventral cochlear nucleus of the cat. A study with the electron microscope. Neuroscience 4: 1925-1945.

Dingledine, R., J. Dodd, and J. S. Kelly (1980) The in vitro brain slice as a useful neurophysiological preparation for intracellular recording. J. Neurosci. Methods 2: 323-362.

Evans, E. F., and P. G. Nelson (1973) The responses of single neurons in the cochlear nucleus of the cat as a function of their location and the anaesthetic state. Exp. Brain Res. 17: $402-427$.

Hackett, J. T., H. Jackson, and E. W. Rubel (1982) Synaptic excitation of the second and third order neurons in the avian brainstem. Neuroscience 7: 1455-1469.

Kiang, N. Y. S., J. M. Rho, C. C. Northrop, M. C. Liberman, and D. K. Ryugo (1982) Haircell innervation by spiral ganglion cells in adult cats. Science 217: 175-177.

Lenn, N. J., and T. S. Reese (1966) The fine structure of nerve endings in the nucleus of the trapezoid body and the ventral cochlear nucleus. Am. J. Anat. 118: 375-390.

Liberman, M. C. (1982) Single-neuron labeling in the cat auditory nerve. Science 216: 1239-1241.

Lorente de Nó, R. (1933a) Anatomy of the eighth nerve. The central projection of nerve endings of the internal ear. Laryngoscope (St. Louis) 43: 1-38.
Lorente de Nó, R. (1933b) Anatomy of the eighth nerve. III. General plan of the structure of the primary cochlear nuclei. Laryngoscope (St. Louis) 43: 327-350.

I,orente de Nó, R. (1981) The Primary Acoustic Nuclei, Raven Press, New York.

Martin, M. R. (1981) Morphology of the cochlear nucleus of the normal and reeler mutant mouse. J. Comp. Neurol. 197: 141-152.

Martin, M. R., and J. W. Dickson (1982) Inhibition of nonprepotential units in the anteroventral cochlear nucleus. Abstracts of the Association for Research in Otolaryngology 1982: 6.

Molnar, C. E., and R. R. Pfeiffer (1968) Interpretation of spontaneous spike discharge patterns of neurons in the cochlear nucleus. Proc. IEEE 56: 993-1004.

Osen, K. K. (1969) Cytoarchitecture of the cochlear nuclei in the cal. J. Comp. Neurol. 136: 453-484.

Pfeiffer, R. R. (1966a) Classification of response patterns of spike discharges for units in the cochlear nucleus: Tone-burst stimulation. Exp. Brain Res. 1: 220-235.

Pfeiffer, R. R. (1966b) Anteroventral cochlear nucleus: Wave forms of extracellularly recorded spike potentials. Science 154: $667-668$.

Rasmussen, G. L. (1967) Efferent connections of the cochlear nucleus. In Sensorineural Hearing Processes and Disorders, A. B. Graham, ed., pp. 61-75, Little, Brown \& Co., Boston.

Rhode, W. S., D. Oertel, and P. H. Smith (1983) Physiological response properties of cells labelled intracellularly with horseradish peroxidase in cat ventral cochlear nucleus. J. Comp. Neurol. 213: 448-463.

Romand, R. (1978) Survey of intracellular recording in the cochlear nucleus of the cat. Brain Res. 148: 43-65.

Rose, J. E., R. Galambos, and J. R. Hughes (1959) Microelectrode studies of the cochlear nuclei of the cat. Bull. Johns Hopkins Hosp. 104: 211-251.

Ryugo, D. K., and D. M. Fekete (1982) Morphology of primary axosomatic endings in the anteroventral cochlear nucleus of the cat: A study of the endbulbs of Held. J. Comp. Neurol. 210: $239-257$.

Spoendlin, H. (1969) Innervation patterns in the organ of Corti of the cat. Acta Otolaryngol. 67: 239-254.

Starr, A., and R. Britt (1970) Intracellular recordings from cat cochlear nucleus. J. Neurophysiol. 33: 137-147.

Webster, D. B., and D. R. Trune (1982) Cochlear nuclear complex of mice. Am. J. Anat. 163: 103-130. 